\title{
Maternidad lesbiana: otra cara del cambio social desde un enfoque etnográfico
}

Diana Lanzarote Fernández

IES Emilio Pérez Piñero, Calasparra, Murcia

\author{
LESBIAN MOTHERHOOD: ANOTHER SIDE OF SOCIAL CHANGE \\ FROM AN ETHNOGRAPHICAL APPROACH
}

\section{Resumen}

Este artículo explora, a través de una metodología cualitativa, la experiencia de la maternidad lesbiana, reconociéndola como experiencia genuina de formas de parentesco asociada al cuidado y al tiempo transcurrido con el otro, lo que se interpreta como una forma de la mutualidad del ser en Sahlins, donde lo biológico deviene metáfora de algo que se vive como proceso. Además, el ejercicio y visibilidad de maternidad lesbiana se construye socialmente, poniendo en discusión mitos sobre la identidad lesbiana y a su vez, participando activamente en el cambio social percibido como un proceso de larga duración, de paulatino alejamiento de formas estáticas del parentesco y las relaciones sociales hacia una visión no necesariamente individualista (fundada en la "libertad de elegir") pero sí procesual y dinámica de los mismos.

Palabras clave

Parentesco; parentesco queer; maternidad lesbiana; antropología feminista; cambio social

Códigos JEL: B50, Y40, J12, K30

\section{Abstract}

This paper explores, through a qualitative methodology and an ethnographic approach, the experience of lesbian motherhood, recognizing it as a genuine kinship experience, associated with the care and the time spent together. It is interpreted as a form of the "mutuality of being" in Sahlins, where the biological becomes a metaphor of something that is experienced as a process. In addition, the exercise and visibility of lesbian motherhood is socially constructed, putting into discussion myths about lesbian identity and, at the same time, actively participating in social change, perceived as a long durée process, gradually moving away from static forms of kinship and social relations, towards a vision not necessarily individualistic (based on the "freedom to choose") rather a process-like and dynamic one.

Keywords

Kinship; queer kinship; lesbian motherhood; feminist anthropology; social change

JEL codes: B50, Y40, J12, K30

Fecha de recepción del original: 22 de febrero de 2021; versión definitiva: 21 de noviembre de 2021.

Diana Lanzarote Fernández. Licenciada en Filosofía. Doctora en Historia Social. IES Emilio Pérez Piñero (Calasparra, Murcia). Tel.: +34 627558 089; E-mail: dianalanzarote@lanzarote-ranz.com; ORCID ID: https://orcid.org/0000-0001-7981-8400. 


\section{Maternidad lesbiana: otra cara del cambio social desde un enfoque etnográfico}

Diana Lanzarote Fernández

IES Emilio Pérez Piñero, Calasparra, Murcia

Introducción

Lejos quedan los tiempos en los que la escritora norteamericana Janet Flanner afirmaba jocosa en una carta a Djuna Barnes, refiriéndose a una amiga común: “Ha adelgazado mucho pero está con su mente despierta a los noventa años; las lesbianas tienen unas vidas tan sanas [...] nada de embarazos, nada de partos, nada de abortos" (Tatafiore, 1991). Sin embargo, hoy, quizá la maternidad lesbiana sea una de las caras más impactantes del cambio social en el que vivimos inmersos.

No hace tanto tiempo de este cambio, que ha implicado normalización y visibilidad, pero pasar de la vergüenza al orgullo no ha sido fácil. Es verdad que desde los tiempos del desprestigio social de la sospechosa soltería en las mujeres, desde el tradicional ocultarse de las amigas a vanagloriarse de ser madres fuera del sistema de control patriarcal, a decirse dueñas de sus cuerpos y de sus proyectos de vida, median en nuestro país solo algunos decenios ${ }^{1}$.

La eclosión del feminismo ha transformado paulatinamente las relaciones sociales, políticas y económicas hasta el punto de poder hablar de una crisis de legitimación patriarcal (Cobo, 2013) que sin duda ha tenido un fuerte impacto no solo en las estructuras del poder y las instituciones, sino también en las vidas íntimas, en ámbitos familiares y personales.

Visto solo desde España, y sabiéndola parte de un contexto internacional con movimientos sociales y cambios legales similares, la Ley del Divorcio de 1981 y la Ley de Reproducción Asistida de 1988 son los dos hitos que nominalizan y contractualizan los dos pilares de la sujeción de las mujeres: el matrimonio y la reproducción (De Beauvoir, 1998). Ambas leyes han tenido sus revisiones ${ }^{2}$ llevadas a

\footnotetext{
${ }^{1}$ La Ley de Peligrosidad Social y Rehabilitación Social (LPRS) de 1970 y fue derogada solo en 1979. Sustituía a la Ley de Vagos y Maleantes de 1954, heredera de la instaurada durante la Segunda República. Esta última no incluía sin embargo la persecución de homosexuales, como sin embargo sí preveía el Código Penal de 1928 de Primo de Rivera.

2 Las últimas y de momento vigentes en lo referente al divorcio y la reproducción asistida: Ley 15/2005 de 8 de julio, por la que se modifican el Código Civil y
}

cabo entre los años 2005 y 2006. Aun así, la ley que en el nivel estatal se revela también fundamental para muchas mujeres es la de del 1 de julio de 2005, por la que gays y lesbianas pueden contraer matrimonio en las mismas condiciones que el resto de los españoles ${ }^{3}$. De este modo no solo transforma la vida de las lesbianas sino también la de la sociedad en su conjunto, pues con sus vidas visibles entran en juego y cambian el escenario social, y sus representaciones familiares ponen a todos frente a la necesidad de reconsiderar nuestras ideas sobre el parentesco y qué prejuicios subyacen a nuestras concepciones (Cadoret, 2012). De igual modo fuerzan a reflexionar sobre nuestras leyes, la relación de las mismas con el individuo, la naturaleza del derecho civil, la relación del Estado con la sociedad (Glendon, 1989), e incluso nos invitan a preguntarnos de qué manera afecta a la democracia el mantenimiento de nuestros paradigmas.

Pero ¿era esto lo que deseaban? ¿Poder casarse?

En el ámbito de reflexión académica feminista, como en los movimientos sociales, ha cabido preguntarse si el matrimonio es de hecho un horizonte deseable (Trujillo y Falguera, 2019) y si en todo caso, en un tiempo en que la institución matrimonial parece perder terreno, en los tiempos del démariage (Théry 1993), es realmente casarse el objetivo de las que hasta ahora habían sido las sexualidades disidentes (Butler, 2002). Se pregunta Butler si

la Ley de Enjuiciamiento Civil en materia de separación y divorcio; Ley 14/2006 de 26 de mayo.

3 Ley 13/2005 de 1 de julio por la que se modifica el Código Civil en materia de derecho a contraer matrimonio. Con anterioridad el Parlament de Cataluyna había legislado a favor de la adopción por las parejas del mismo sexo de los hijos de la pareja, lo que resolvía en cierto sentido que las parejas lesbianas que habían concebido hijos al abrigo de la ley de Reproducción Asistida de 1988, o que los tenían en adopción o por relaciones sexuales anteriores pudieran adoptar a los que eran sus hijos de hecho. (31 de marzo de 2005) 
en realidad el problema no estará en la filiación -como de hecho se ha puesto de manifiesto en algunos países como España, Francia o Italia- más que en el acceso o no a una institución que ha devenido simplemente contractual, sospechando que el parentesco es algo más profundo que la "familia post-divorcio", algo que está más enraizado en lo que se ha llamado "orden simbólico" y que está definido como heterosexual, algo que también detectan Donoso (2013) y Trujillo y Falguera (2019).

En efecto en la actualidad nos encontramos ante un uso de las tecnologías de la reproducción asistida que ha transformado como nunca antes nuestro concepto de filiación y pone en jaque de manera inédita nuestra imagen tradicional de qué es una familia (Brunet, 2011), porque si usadas por parejas heterosexuales no han afectado a la representación social de la familia, tal y como lo ha hecho el uso lesbiano de tales técnicas.

Por otro lado, entrar en la vida legal hace emerger el temor de ser asimiladas u homogeneizadas, y en este sentido también se oyen voces críticas desde el feminismo lesbiano (Ettelbrick, 1989) ¿Se traicionan a sí mismas? ¿Se acabó con la visibilidad la vida sana y despreocupada a la que se refería Flanner? ¿Es un logro o en el logro va inserta la negación de la propia idiosincrasia? Lo que a la postre sugiere el debate de fondo: predicar de alguien que es lesbiana, ¿es una descripción o contiene de algún modo un sesgo normativo? El debate no está exento de paradojas y remite sin duda a la dicotomía universalidad-identidad.

Metodología de la investigación etnográfica

Con la presente etnografía se ha pretendido dar voz a algunas lesbianas y hacer emerger también, desde una perspectiva emic, cómo viven, no ya las conocidas resistencias legales que lentamente evolucionan, sino su cotidianidad, cómo forman sus familias, si se adaptan o rodean los límites creando alternativas, y sobre todo qué significa para ellas "ser familia" o si cabe preguntarse si es cierto que se sienten asimiladas a un esquema heteronormativo (Descoutures 2010).

La recogida de datos está vinculada parcialmente a una investigación predoctoral en la que se mantuvo contacto- entre otros tipos de familia, pues el objetivo de la investigación era más amplio4- con un total de siete mujeres lesbianas madres no biológicas y/o no jurídicas (Ricard 2001, citado en Imaz 2016b). El objetivo en aquella ocasión era tratar de comprender la experiencia de estas mujeres, su visibilidad y sus estrategias de emparentamiento e inserción en la realidad familiar. Se trató de responder a preguntas tales como si había o no un sentimiento de reconocimiento pleno por parte de la madre biológica/jurídica, si

4 Lanzarote Fernández, D. (2017) Retos de las familias contemporáneas y representaciones del parentesco en el siglo XXI, Universidad de Murcia (Tesis inédita). la voluntad de ser madres había sido compartida y de qué manera, qué significaba ser la madre no gestante, cuál era el lenguaje de parentesco usado por ellas, en qué elementos fundaban la producción del parentesco o cómo había sido su experiencia en el ámbito de la familia extensa, los amigos o las instituciones. Este interés estaba inserto en otro más general referente a representaciones alternativas del parentesco respecto al esquema biologicista hegemónico. En el estudio encontraban acomodo otras formas familiares, críticas con las lógicas de la sangre, como parejas heterosexuales adoptantes y familias reconstituidas. Agrupándolas bajo una misma hipótesis, se desordenaron las clasificaciones sociológicas estándar buscando patrones posibles para una reflexión sobre una representación performativa del parentesco (Leach 2004, Needham 1977). En todos los casos el interés estuvo centrado en la persona no implicada biológico-genéticamente con los demás integrantes de la familia y en los modos en que se le vinculaba a la unidad familiar.

La hipótesis de trabajo partía de que la familia lesbiana, como las demás participantes en el estudio, se reforzaba precisamente en la asunción generalizada de que el vínculo del parentesco se construye socialmente y que su naturaleza es precisamente procesual y relacionada con el cuidado. Lo biológico sería un elemento meramente instrumental en la construcción del proyecto vital familiar. En ese sentido, la experiencia de la maternidad lesbiana resultaba, junto con otras familias no convencionales, uno de los "buques insignia" de un ya imparable cambio social hacia un progresivo concepto nominalista y constructivista del parentesco, que más pronto o más tarde, habría de tener consideración legal.

En este sentido parecía adecuado el enfoque etnográfico y cualitativo, sin menoscabo de la incuestionable utilidad del dato estadístico, incluso si es escaso pues el conocimiento de la vida lesbiana es aún asunto pendiente como han observado diversos autores (Cortina, 2016; Imaz, 2006).

En este artículo se acotará el campo al de las mujeres lesbianas que fue utilizado entonces y en la medida de lo posible reanalizar algunas de aquellas informaciones a la luz de nuevas preguntas y en algunos casos de una nueva entrevista, pues ha resultado posible realizar un seguimiento de algunas de estas experiencias. Sin poder considerarse un estudio longitudinal, ello ha permitido revisar datos o refrendarlos y actualizarlos donde ha sido preciso. De igual modo se restringirá el interés del presente artículo a (1) sus concepciones sobre qué es una familia y qué papel juega el elemento bio-genético en ella, (2) cuál es la substancia del parentesco para ellas, (3) si sienten que siguen modelos impuestos y (4) si en ello creen perder algo de su idiosincrasia. En los casos en que ha sido posible se ha integrado para esta nueva visión el punto de vista de la madre biológica. Las entrevistas, en profundidad y semiabiertas, fueron grabadas y transcritas en su totalidad si bien para el análisis se han tomado determinados fragmentos que se presentarán a lo largo del artículo. A las narrativas de las siete primeras informantes se han añadido las de cinco más para esta etnografía. La Tabla 1 presenta con el fin de facilitar el seguimiento de la misma. 
Tabla 1: perfiles de las entrevistadas

\begin{tabular}{|c|c|c|c|c|c|c|c|}
\hline $\begin{array}{c}\text { Entrevistada/ } \\
\text { madre bioló- } \\
\text { gica o no }\end{array}$ & $\begin{array}{c}\text { Pareja/ en- } \\
\text { trevistada o } \\
\text { no (año) }\end{array}$ & Estado civil & $\begin{array}{l}\text { Número de } \\
\text { hijos }\end{array}$ & $\begin{array}{c}\text { Modo de ac- } \\
\text { ceso a mater- } \\
\text { nidad }\end{array}$ & $\begin{array}{l}\text { Madre jurí- } \\
\text { dica }\end{array}$ & $\begin{array}{c}\text { Primera } \\
\text { entre- } \\
\text { vista }\end{array}$ & $\begin{array}{l}\text { Segunda } \\
\text { entrevista }\end{array}$ \\
\hline Rosa/no & Ana/sí (2020) & Casadas & 1-Víctor & TRA & ambas & 2017 & 2020 \\
\hline María/no & Clara/no & Casadas & $\begin{array}{l}\text { 2- Óscar y } \\
\text { Silvia }\end{array}$ & TRA & ambas & 2017 & 2020 \\
\hline Isa/no & $\begin{array}{l}\text { Carmen/sí } \\
\text { (2018) }\end{array}$ & Casadas & 2- Pablo e Iris & $\begin{array}{l}\text { Relación hete- } \\
\text { rosex. anterior }\end{array}$ & Carmen & 2017 & 2020 \\
\hline $\begin{array}{l}\text { Esther/sí } \\
\text { primera hija/ } \\
\text { no segundo } \\
\text { hijo }\end{array}$ & $\begin{array}{l}\text { Laura/sí } \\
\text { (2020) }\end{array}$ & $\begin{array}{l}\text { Casadas(2a } \\
\text { nupcias para } \\
\text { Esther, divor- } \\
\text { ciada de Cati, } \\
\text { madre no } \\
\text { biológica de } \\
\text { Alba) } \\
\end{array}$ & $\begin{array}{l}2(1+1) \text { Alba } \\
\text { (biológi- } \\
\text { camente } \\
\text { Esther) } \\
\text { Daniel (bio- } \\
\text { lógicamente } \\
\text { Laura) }\end{array}$ & $\begin{array}{l}\text { 1a hija de rela- } \\
\text { ción lesbiana } \\
\text { anterior } / 2^{\circ} \text { hijo } \\
\text { común TRA }\end{array}$ & ambas & 2020 & ---- \\
\hline Erica/no & $\begin{array}{l}\text { Vittoria/sí } \\
\text { (2017) }\end{array}$ & Unión Civil & 1- Serena & Acogida & $\begin{array}{l}\text { Sin reconoci- } \\
\text { miento }\end{array}$ & \begin{tabular}{|l} 
Ambas \\
2017
\end{tabular} & ---- \\
\hline Carla/no & \begin{tabular}{|l} 
Sonia/sí \\
(2017)
\end{tabular} & Unión Civil & 1- Vania & $\begin{array}{l}\text { Adopción trans- } \\
\text { nacional }\end{array}$ & Sonia & \begin{tabular}{|l} 
Ambas \\
2017 \\
\end{tabular} & --- \\
\hline Cecilia/sí & Sandra/no & Casadas & $\begin{array}{l}\text { 2- mellizas: } \\
\text { Lucía y Cris }\end{array}$ & TRA & Ambas & 2020 & ---- \\
\hline Daria/no & Bea/no & Unión civil & Sin hijos & ---- & ---- & 2019 & ---- \\
\hline
\end{tabular}

Fuente: elaboración propia.

Nota: las entrevistas a mujeres italianas se han desarrollado originariamente en italiano y se han traducido para facilitar su comprensión en este artículo.

Constructivismo Lesbiano y parentesco: La mecánica biológica como instrumento

Etnografía de familias lesboparentales.

Las parejas lesbianas ofrecen una flexible actitud coparticipativa ante el vínculo biológico. Promotoras particularmente visibles de la crisis de legitimación patriarcal, y usuarias de excepción de las técnicas de reproducción asistida (TRA), parecen dar mucha importancia al vínculo biológico con los hijos (Pichardo, Stéfano y Martín, 2015). Ello constituye un extremo interesante para la indagación cualitativa, no solo por desentrañar el sentido del dato estadístico, aún escaso, sino por conocer cuáles son sus motivos explícitos, sus discursos y en qué medida lo es o de qué manera interpretan las parejas lesbianas el vínculo biológico. Parece además deseable una revisión empíricocualitativa a fin de salvar un posible sesgo heteronormativo en el análisis de sus estrategias y narrativas en torno a la familia y el parentesco, pues vistas desde una perspectiva que pudiera resultar, por pretenderse igualitaria, en exceso asimilacionista respecto al modelo hegemónico, podría hacer perder de vista en pro de la igualdad, la diferencia de estas familias si la hubiere (Domínguez y Montalbán, 2016).

Los avances de la ciencia médica en materia de reproducción asistida son en cierto sentido aún recientes y por ello, unido a la lenta evolución del marco legal, no ya en nuestro país, sino en ámbito internacional ${ }^{5}$, era tradicional en las parejas lesbianas, por lo demás invisibles, que la maternidad conjunta se produjera a partir de la aceptación, por parte de una de las mujeres, de los hijos de la otra, habidos de una relación heterosexual anterior (Pichardo, Stéfano y Martín, 2015).

A partir del reconocimiento de sus derechos a una filiación conjunta como madres, tal modelo ha entrado sin duda en declive en favor del uso de las técnicas de reproducción asistida (Cortina, 2016), coexistiendo con otros como el de la familia lesbiana reconstituida, donde también hay integración de hijos habidos en otras relaciones, pero que provienen de un matrimonio y divorcio lesbianos, o la también minoritaria adopción, al menos en los países en los que tal opción es legalmente posible. No obstante, los datos sobre familias lesboparentales son como se ha afirmado aún escasos ${ }^{6}$. En 2011, la mayor parte

\footnotetext{
5 En Italia, la ley de Uniones Civiles, llamada Legge Cirinnà, de 2017, no prevé la posibilidad de utilización de las TRA a mujeres solas o parejas lesbianas en Italia y está siendo objeto de debate el proyecto de la Ley Bioética de Reproducción Asistida en Francia presentada por E. Macron en 2020 que abriría el uso de las TRA a las mujeres solas y parejas lesbianas.

${ }^{6}$ https://www.elmundo.es/elmundo/2012/01/24/espana/1327403431.html
} 
de las familias "arcoiris" son reconstituidas a partir de relaciones heterosexuales anteriores $(58,62 \%)$ mientras que las que acceden a la maternidad a través de TRA son un $31,82 \%$ y por adopción un 11,36\% (Imaz, 2016a). Sin embargo, Cortina (2016), insistiendo en que apenas hay datos disponibles, toma el estudio de Agustín Ruiz, de 2013, del que se desprende que un $5,6 \%$ tiene hijos de relaciones heterosexuales anteriores, el 73,2\% por reproducción asistida, el 15,5\% por adopción, el 4,2\% por acogida y el $1,2 \%$ por acuerdo con una persona heterosexual. Pichardo, Stéfano y Martín (2015) afirman que en el marco de su estudio sobre unas 400 encuestas la opción mayoritaria es la del uso de las TRA las familias accedieron a la paternidad y la maternidad a través de la inseminación clínica (41\%) y a partir de la autoinseminación en el hogar (12\%), lo que suma un 53\% de uso de las propias capacidades reproductivas (médicamente asistidas o no) y que solo en un $33 \%$ se manifestaba la adopción y en un $9 \%$ de los casos los hijos provenían de relaciones heterosexuales. Por otro lado, ya a finales de 2020, en una comunicación, a efectos de redacción del presente artículo, con la Asociación de Familias Gays y Lesbianas Asfagalem, la portavoz comunicaba la misma perplejidad en torno a los datos estadísticos: no hay apenas información.

Parece, según lo expuesto, especialmente interesante la opción mayoritaria, no solo por serlo sino porque, abordada de forma cualitativa, ofrece la ocasión para la reflexión en torno a sus representaciones del parentesco en relación con la biología, así que servirían sin duda, no ya a conocer a las lesbianas como parte de la sociedad y actoras sociales, parte activa del cambio social, sino a proveernos de datos empíricos para una discusión ulterior y más general en lo referente a la naturaleza del parentesco.

Es cierto, a la hora de fundar sus hogares, las parejas lesbianas convertidas ya en madres visibles, tienden a poner en juego la propia capacidad reproductiva, lo que podríamos interpretar como una forma de apropiación del cuerpo y sus posibilidades, que podría constituir una versión heterodoxa del apropiarse de sus cuerpos a través de una defensa de la función materna. Las lesbianas en este sentido han reconciliado dos realidades aparente e históricamente autocontradictorias, a saber, la de la lesbiana y la de la madre contribuyendo así a la transformación del lesbianismo y de la maternidad, lo cual no ha estado exento de polémica tanto desde la perspectiva queer como desde instancias conservadoras. De hecho, su uso de las técnicas de reproducción asistida parece un recurso contra el feminismo radical de los años 60 que vio en el uso de tales técnicas un giro de tuerca más del patriarcado (Puigpelat, 2011).

Cabe hacer sin duda una crítica al uso de las TRA como un posible exceso de medicalización del cuerpo de las mujeres, y por tanto también de las lesbianas. De hecho, es vigente incluso la reivindicación del derecho a la filiación de sus hijos sin obligación de presentar documentación que atestigüe un proceso de inseminación o FIV médicamente asistida. Muchas lesbianas lo perciben como un elemento fundamental de su autonomía reproductiva, además de exigible como trato igualitario con respecto a las parejas heterosexuales, que no deben dar cuenta del procedimiento, íntimo o sanitario, por el que han llegado a ser padres, pues hasta la fecha, para el registro de recién nacidos de parejas lesbianas debía aportarse libro de familia y documentos de una clínica de fertilidad?

Es cierto que la presunción de paternidad sociológica, que tiene su origen en motivos de orden público (Brunet, 2011), subsiste dentro del matrimonio (art. 116 Código Civil Español), pero no solo, incluso, fuera del mismo (art. 119 C.C.). Tanto es así que aunque la veracidad no exista en caso de parejas no casadas, es habitual que en los Registros Civiles no se pregunte ni se pida documentación alguna al varón que acompaña a una mujer a inscribir un recién nacido (etnografía propia, en el presente trabajo: Carmen, 2018)

Sin embargo, para ejercer tal derecho y no vincular su proceso de concepción a una clínica, deben adquirir el semen en bancos de esperma, lo cual suscita la idea de mercantilización de gametos y no tanto de don, como ha sido estudiado por Álvarez y Pichardo (2017). El corolario político de tal mercantilización además supondría dejar a atrás, los derechos reproductivos que eran la reivindicación real del feminismo, y no tanto el "derecho a elegir" que parece describir el parentesco y la creación de la familia contemporánea (Imaz, 2016a).

La cuestión sobre si el "nuevo parentesco" es de tipo electivo o no, es en todo caso, en orden a dilucidar algunas ideas sobre la naturaleza del parentesco, muy interesante si se mira desde un prisma un poco más amplio que el de la mera oposición entre parentesco biológico o elegido, a saber, la idea constructivista del mismo, que M. Sahlins ha denominado mutualidad del ser, que supone la copresencia, la participación fundamental en la vida de otro y la dividualidad, saberse el resultado de una pluralidad (Strathern, 1988). No sería biológico y no sería electivo. Sucede performativamente en un contexto social, por lo que podríamos aventurar que por eso no es biológico, pero también por eso no es electivo. La presente etnografía aborda esta cuestión con las informantes.

Experiencia genuina

Según lo observado a menudo en las parejas lesbianas se someten ambas mujeres de la pareja a técnicas de reproducción asistida, con semen del mismo o distinto donante, bien porque ambas desean hacerlo o bien porque prueban suerte, una o la otra, valiendo lo mismo para la pareja quien de las dos lo logre, como también se ha observado (Imaz, 2016b). A menudo el deseo de ser madre y de experimentar el embarazo y el parto en el propio cuerpo es profundo y viene de la infancia y lleva a algunas de estas mujeres, si bien no lo identifican con un instinto (Ba-

\footnotetext{
7 https://www.pikaramagazine.com/2017/06/autogestion-reproductiva-lesbianas/
} 
dinter, 1991), a una persistencia que supone sin duda una medicalización importante para lograrlo, la cual aceptan como inevitable:

"Hemos probado a inseminarnos las dos pero yo no pude por problemas físicos [...] al final lo hizo mi mujer" (María, 2017).

“Era lo que más deseaba en el mundo, lo intenté cuatro veces, cuatro años con cuatro operaciones [...], al final estaba agotada [...] cuando vi en ella lo que tanto deseaba en mí fue extraño, pero muy bonito" (Rosa, 2017).

“[...] cuando me hormoné para las FIV tampoco sentí miedo, pero cuando me dijeron que tenía que operarme porque la cicatriz interna de la cesárea anterior no permitía que concibiese de nuevo ya dudé. De hecho, Isa dijo que ya lo hacía ella" (Carmen, 2018).

"A ver, es lo que hay, si no quieres tener relaciones con hombres... tendrás que tomar hormonas y comprar el semen..." (Ana, 2020).

"La madre gestante fui yo sí [...] es que yo siempre quise ser madre, desde muy pequeña yo decía a todo el mundo, yo voy a tener una hija que se va a llamar Alba" [...] "claro que tienes que hormonarte, porque es más fácil, es que además si es así artificialmente [...] es lo que hay [...] aunque hay quien lo hace sin tomar nada" (Esther, 2020).

A veces el deseo de ser madre no proviene de una motivación personal, sino derivada de sentirse parte de un proyecto:

"La verdad que yo sabía que era lesbiana desde muy joven y entonces no se sabía nada de reproducción asistida ni nada de eso [...] así que desde siempre pensé que no me iba a casar ni a tener hijos ni nada de eso, pero luego con ella, que para ella era tan importante [...] y viendo que lo estaba pasando tan mal por no lograrlo [...] le dije, mira, para un poco [...] lo intento yo si quieres y luego si te sientes con fuerzas vuelves a probar [...] y lo hice, y fue fácil en comparación [...] y la verdad es que es lo más bonito que he vivido nunca [...] también te digo que tuve un embarazo muy bueno" (Ana, pareja de Rosa, 2020).

"No lo había pensado nunca, entiéndeme, yo he tenido novios, así que supongo que pensaba que tendría hijos como todo el mundo, pero claro, al vivir dentro del armario diez años con Sandra es que ya no lo piensas, pero luego cumplí treinta y cinco y pensé, o ahora o nunca y fue fácil, a la primera" (Cecilia, 2020).

Según parece el estar "dentro del armario" hizo que la informante descartara durante un decenio siquiera el pensarlo. Las condiciones legales y sociales pueden ser de una importancia no indiferente en los planes de fundar una familia con niños, tanto como las económicas.
"Sí, me preparé la oposición pensando, si gano la plaza no espero [...] pero antes no lo habría hecho nunca" (Carmen, 2018).

"mujer, pues claro que me esperé a tener un trabajo fijo para tener a Alba [...] por supuesto, y a tener pareja, también, no quería tenerla sin una familia, quería el pack completo" (Esther, 2020).

A propósito del origen del deseo reproductivo y del desarrollo que se permiten del mismo, parece interesante contrastar las narrativas de estas mujeres lesbianas españolas con las de madres lesbianas italianas, de modo que nos permita examinar cómo el marco legal puede influir en los discursos y las experiencias y, aún así, comprobar que la insistencia y la lucha es similar en las parejas españolas e italianas entrevistadas aunque con resultados desiguales:

Erica y Vittoria son una pareja italiana que conviven desde 2009. Iniciaron su proceso en clínica y ante la dificultad económica para seguir intentándolo tras numerosos intentos, adquirieron el semen en un banco de esperma y optaron por la autoinseminación:

"Entonces habíamos probado el camino de la fecundación asistida en el extranjero, porque sabes que aquí (en Italia) no se puede. Miramos en varias clínicas, una en Barcelona y algunas en Dinamarca. Al final nos decidimos por una danesa [...] hicimos cuatro intentos, cinco viajes, cuatro inseminaciones, y ninguna llegó a buen puerto... Después, hicimos dos inseminaciones en casa" (Erica, 2017).

"Al principio yo no estaba muy motivada la verdad, pero poco a poco, esto se fue haciendo un hueco dentro de mí, y al final me involucré hasta el punto de probar yo misma" [...] "de todos modos te enfrentas a esto desorientada porque sabes que nunca vamos a poder adoptar la una o la otra aquí" (Vittoria, compañera de Erica, 2017).

"La ley Cirinnà yo creo que ha sido lo máximo que vamos a lograr aquí, ya es mucho que nos dejan legalizar nuestra vida un poco como Unión Civil [...] pero adoptar la una el hijo de la otra, ni lo sueñas. Esto es Italia, sabes, aquí tenemos el Vaticano hasta en la sopa" (Daria, 2019).

Aunque menos, hay parejas lesbianas que llegan a ser madres por vías no biológicas, pues ninguna de las dos siente esta necesidad de "tener la experiencia". Carla y Sonia, de Vicenza en Italia, son pareja desde 2011. Carla no quiere "probar tal sensación"y según afirma no ha pensado nunca en ello atribuyéndolo a su consciencia de ser lesbiana, a los límites legales y a los recursos económicos:

"Sabes, yo es que sabía que era lesbiana desde muy pequeña [...] yo creo que creces pensando claramente que no lo harás; cuando eres pequeña no sabes nada de fecundaciones asistidas [...] menos aún hace veinte años... De todos modos, en Italia es imposible [...] tienes que tener dinero para irte al extranjero... quiero decir 
que no es que lo excluyera yo [...] es que estaba verdaderamente fuera del horizonte" (Carla, 2017).

Sonia, italiana de origen neozelandés, estuvo anteriormente casada con un varón y llegó a concebir la idea de tener hijos, pero no lograrlo no le causó, según afirma, gran dolor ni ello la empujó a probar suerte con las técnicas de reproducción asistida, que en su caso, como mujer heterosexual casada entonces, en Italia, habrían estado permitidas:

“Lo pensé un tiempo [...] y mi ex-marido y yo llegamos a considerar usar esas técnicas, pero enseguida comprendí que no quería recorrer ese camino [...] y después, cuando me divorcié, me di cuenta de que en ese sentido me sentía muy tranquila, había aceptado muy bien no que lo iba a hacer, a mí no me parece que se trate de ningún instinto la verdad, yo creo que le llaman así como para decir que te importa mucho" (Sonia, 2017).

En todo caso, y a juzgar por lo que parece una opción decidida por las técnicas de reproducción asistida, podría pensarse que en efecto el vínculo biológico tiene mucha importancia para las madres lesbianas, si bien, según se desprende de sus narrativas, más en tanto que experiencia vivida en primera persona por la madre gestante que por una clase adscripción a la ideología de la sangre o un sentido fuerte de la idea de descendencia genética. Contrariamente a lo que un prejuicio biologicista o familista podría a hacernos pensar, en la experiencia materna lesbiana el sentido de lo biológico está según parece circunscrito a "vivir la experiencia".

"simplemente quería tener esa experiencia, ver cómo cambia tu cuerpo, eso... me apetecía mucho... pero ahora veo que era una tontería" (Rosa, 2017).

"Sí, a ver, era importante hacerlo, protagonizar eso [...] vivirlo, no porque se me parezca [...] me gusta pensar que se parecen a Isa [...] es que quería vivirlo" (Carmen, 2018).

"sí, es importante [...] si te dijera que no te mentiría [...] sí importa [...] pero también te digo que igual que lo siento con Alba [...] eso no me limita ni me cambia con Dani, que lo tuvo Laura [...] es raro porque en realidad [...] siento la importancia de esa experiencia con Alba, pero de igual modo Dani es mi hijo completamente [...] no me cabe duda ni lo siento menos" (Esther, 2020).

"Para mí fue lo más bonito que he vivido, como te decía antes, pero es que no me lo esperaba [...] porque ni había pensado yo en hacerlo nunca, estaba tan claro que era Rosa la que iba a hacerlo [...] pero si me dices por si para mí es importante que se me parezca [...] a mí me da igual a quién se parezca mi hijo [...] es que ni pienso en eso [...] a mí me da igual [...] es mi hijo y punto" (Ana, 2020).

Incluso ante las nuevas familias y las formas alternativas de pensar y construir el parentesco una idea recurrente es la del parecido. Está presente en los discursos de familias adoptantes y en los de padres y madres no biológicos en general, gays, lesbianas o heterosexuales. El prestigio del parecido en cuestiones de parentesco parece provenir de la propria naturaleza.

"Cuando veo a Iris es como si fuera yo misma... como si tuviera una segunda oportunidad" (Carmen, 2018).

"Es normal que todo el mundo quiera que se le parezcan los hijos, te ves reflejado en ellos, es un poco egocéntrico, además es tu zona de confort, es lo conocido, creo yo, pero es que en la naturaleza es así, el que se te parece es tuyo y lo proteges, estás protegiendo tus genes" (Cecilia, 2020).

Resulta interesante escuchar a Cecilia este discurso biologicista al tiempo que defiende que Sandra es la madre de las mellizas cuanto ella. A Carmen el parecido de su hija parece proporcionarle la ilusoria esperanza de tener "una segunda oportunidad". La biología se desdibuja. A propósito de estas ideas habría que recordar la afirmación de Sahlins (2013) según la cual la biología es de hecho metáfora de la cultura y no al revés, como cuando llamamos "instinto" a algo que en el fondo "solo quiere decir que te importa mucho", y desde ese punto de vista, no solo Cecilia, pero especialmente ella, a través de su reflexión, ilustra esta idea: Por un lado se hace abstracción del donante, por otro se entiende que el parecido es indicio de pertenencia y por otro la maternidad es social. Parece una construcción, una operación mental en la que se valoran y se ignoran elementos y se les da un sentido convirtiéndolos en símbolos del parentesco o despojándolos de significado.

Las madres no biológicas insisten en el parecido:

"eso es un poco social o cultural o como sea [...] algo que la gente quiere ver, basta que digas que es tu hija y empiezan a decir que se te parece... a mí me lo han dicho mucho de tanto verme con Iris sobre todo [...] y yo pienso, sí, en el blanco de los ojos [...] pero cuando hace algunas cosas pienso sin darme cuenta que ha salido a mí" (Isa, 2020).

"a ver, ¿cómo se me va a parecer? Si es rubia platino... y tiene toda la cara de Clara [...] y todo el carácter [...] de hecho chocan mucho. Así como Óscar se lleva mejor con Clara, Silvia es mi monito [...] me imita, me busca [...] en cierto sentido se parece claro [...] me imita mucho" (María, 2020).

"Cuando Alba vuelve de estar con su madre en vacaciones viene hablando como ella, pero se le pasa enseguida [...] a Laura la imita mucho [...] por ejemplo las dos disfrutan mucho pintando [...] Alba la admira [...] yo creo que busca un poco vincularse... más ahora que ha nacido Dani" (Esther, 2020).

Isa afirma que otras personas dicen que su hija se le parece: el parecido, percibirlo, conceder que existe, inventarlo, provocarlo, son modos diversos de decir metafóricamente el parentesco entendido como cercanía y significatividad. 
Sería posible para una reflexión más profunda sobre este "privilegio del parecido" en los discursos de parentesco recordar el ensayo de W. V. Quine, La relatividad ontológica y otros ensayos (1974) en el que el filósofo norteamericano identifica la capacidad de encontrar analogías con algo atávico que está en la base de nuestro conocimiento empírico y nuestra capacidad inductiva. En realidad, el parecido ontológicamente no implica procedencia, sino solo proximidad de caracteres que puede provenir de la mímesis, la proximidad que está implicada en el hecho de "no ser" pero (al menos) "parecer". Es lo más cerca que se puede estar de ser.

Que las familias adoptantes $\mathrm{u}$ otros padres o madres de hijos no biológicos busquen símbolos y parecidos no necesariamente supone que deseen hacer pasar al hijo por bio-genético o que den una importancia fundamental a tales vínculos. El parecido al fin es la metáfora física o gestual en tanto que comportamiento social, la manifestación inequívoca de la proximidad, incluso de pertenencia. Pareciera en este sentido testimonio de copresencia, de participación, de dividualidad. No parecen por lo tanto especialmente víctimas de la fenomanía que estaría presente en las parejas heterosexuales usuarias de TRA (Álvarez y Pichardo 2017)

De hecho, al escuchar a estas madres lesbianas da la impresión de que el uso de las TRA lo viven, más que como una medicalización patriarcal de sus cuerpos y una instrumentalización de sí mismas, como una puesta en acto de sus opciones reproductivas en el ámbito de un uso legítimo y voluntario de los avances científicos en su favor, y lejos de identificar el vínculo biológico con la única verdad del parentesco, afirman llevar a cabo una instrumentalización y con ella, una resignificación de la biología aparentemente pragmática que funciona también como seña de identidad de esa autonomía reproductiva, como también ha observado Imaz (2016a). Así, el parentesco sería más el resultado dinámico, un kinning, un proceso, casi en estado liminal permanente: relaciones sociales que deberían ser estudiadas como tales y no naturalizarlas (Needham, 1977). Podría verse un indicio de la actitud instrumentalizadora aludida en la abstracción hecha del donante en sus narrativas de constitución familiar o la ausencia de protagonismo en el uso de los recursos biológicos de reproducción. Estos además se consideran conjuntamente de la pareja, constituyendo uno de los elementos del emparentamiento, entendido como procesual y basado en la historia comparti$\mathrm{da}$, en algo que viven como una lucha, contra la resistencia natural y contra las resistencias culturales, sociales, legales.

La actitud con respecto al donante por lo tanto se comprende que sea de una completa indiferencia según se desprende de todas las narrativas y remite a una percepción del mismo como sustancia desentrañada. Al ser preguntadas sobre el cuerpo de sus hijos, si no les resulta en algún sentido ajeno o desconocido, suponiendo que ahí está el donante en alguna parte del niño las respuestas obtenidas apuntan a una concepción holista y no parcializada del cuerpo, por lo que se pasa de lo analítico (el semen como elemento aislado, substancia o ingrediente, incluso mercancía) a lo sintético: "nunca se te pasa por la cabeza el donante, el cuerpo de Óscar es el cuerpo de Óscar [...] no es que esta parte es nuestra y esta otra no la conocemos" (María, 2017).

"compramos el esperma en un banco de semen" [...] "claro, es algo que compras [...] es así ¿no?" (Vittoria. 2017).

"Mis hijos provienen de relaciones heterosexuales pero cuando intentamos el método ROPA te digo de verdad que no pensé ni un segundo en si ese embrión era de un donante o no, pensaba que era de lsa y me emocionaba mucho" (Carmen, 2018).

"No pienso en el donante, creo que ha hecho algo para que mujeres como nosotras podamos ser mamás y se lo agradezco, pero eso no lo convierte en un padre" (Esther, 2020).

“nunca pienso en él, no está, aparte de que ha cobrado [...] dicen que no, que es solidario, pero eso es un negocio [...] no, no me siento especialmente agradecida, ¿por qué iba a estarlo?" (Ana, 2020).

En realidad estas actitudes suscitan la cuestión en efecto de quién es el donante, no ya quién es como identificación personal, que queda en España protegida por el anonimato, sino quién quiere ser el donante pues su acción tiene sin duda un significado: se aprecia como una forma, solidaria o no, de extrañamiento, a través del cual se revela como un "querer ser substancia" sin ser persona, externo a la economía del don y la deuda (Mauss, 2010), es decir, sin generar parentesco, lo que lo hace aparecer también como un elemento de la construcción social del mismo. Sin duda la respuesta de Ana parte de la idea de que la compensación económica que el donante recibe es la reciprocidad esperada por el mismo, lo que nos devuelve a una perspectiva de mercado (Bestard, 1998), es decir, neoliberal e individualista (metodológica, epistemológica y éticamente).

De hecho, durante una entrevista se llega a bromear con la idea de que "donante" significa justamente no ser un "padre":

"nosotros éramos cuatro y bueno, mis padres [...] bueno mi madre que fue la que nos crió a todos [...] mi padre sí que era casi un donante (se ríe) [...] sí de verdad, los padres de antes [...] eran donantes prácticamente" (Esther, 2020).

Modelos emergentes de maternidad

La maternidad lesbiana se ha definido a menudo como una contradicción en términos. De hecho, no hay modelos y los que podemos rescatar de la literatura son trágicos, como narra la novela de Patricia Highsmith, Carol, publicada en 1951. La historia de Carol es la de una madre a la que 
se juzga incapaz de educar por ser lesbiana, y por ello una influencia peligrosa para su hija.

Más allá de la cuestión de si influyen o no en la orientación sexual de sus hijos, si son educadoras fiables, si los menores muestran o no diferencias con respecto a otros, criados con familias heteroparentales, extremos que han sido ya estudiados en el pasado por autoras tanto en el extranjero como en nuestro país (Golombok, 1983; Gonzalez et al., 2003), cuando aún resultaba necesario verificar sus capacidades antes de legitimar sus familias, o aplacar las voces ultraconservadoras, lo que podría resultar interesante antropológicamente es si imitan de algún modo a los modelos hegemónicos, y en su caso, si lo hacen por costumbre o por deseo de asimilación, es decir, necesidad de someterse a un modelo aceptado en pro de una visibilidad positiva o para proteger a sus hijos. ¿Están las madres lesbianas sujetas a un esquema heteronormativo? Hay estudios que afirman que, si bien suponen un modo alternativo de familia, no escapan a la influencia de modelos tradicionales (Pichardo et al., 2015).

Para abordar tal cuestión se ha dividido el análisis en dos temas fundamentales: El primero, su propia visión de la familia. Como se sugirió en la reflexión metodológica de este artículo, tiene importancia en orden a pensar el parentesco como cuestión global y, en segundo lugar, por partir de sus ideas y no de un marco heteronormativo impuesto. El segundo tema implicado es si creen que el ejercicio de la maternidad supone una discusión de su identidad como lesbianas o más bien de la maternidad entendida en sentido tradicional.

¿Qué es una familia?

A propósito de qué era el donante para ellas, surgió la pregunta en torno a qué era un padre (y por extensión, una madre) y todas las respuestas fueron en la dirección del cuidado y el tiempo transcurrido juntos, a veces apelaban al apoyo, a la crianza y sugerían que este y no el biológico era el criterio para decidir si alguien es padre o no, tal y como otras investigaciones han puesto de manifiesto (Donoso, 2013). Por otro lado, estas cuestiones limitan muy de cerca con la existencia de la madre no biológica que cifra su maternidad en estos valores y los apuntala además apelando "al parecido".

Un prejuicio familista (biologicista) podría inducir a pensar que en la pareja lesbiana se da una definición de roles distintos como consecuencia de este "vínculo de sangre" con una sola de las madres, esto es, se podría suponer una dicotomía "madre/madrastra", "madre/madrina". Una de las informantes lamenta que aún a veces así sea incluso entre las propias lesbianas:

"hay algunas que se lo toman como si fueran el padre, pero como eran antes los padres, que no construyen el apego, parece que la que pare tiene que hacer el rol de madre [...] y te dan ganas de decirle, pero que te pegues a tu hijo [...] qué tendrá que ver quién lo ha parido [...] al final es que, de no hacerlo, es verdad que los críos reconocen [...] ¿pues a quién van a reconocer y con quién van a tener apego?" (Cecilia, 2020).

Sin embargo, las informantes que participan en esta etnografía, de la mano de una decidida insistencia en que la maternidad nace y crece en la creación del apego, -término que denota cierta idea intensiva de la crianza-, en el cuidado y el tiempo compartido, manifiestan también un interés claro por subrayar que el origen biológico de los niños, entre una y otra madre, no establece diferencia alguna, porque lo que define su familia es el proyecto parental construido juntas, la intención y el deseo compartidos, el largo camino, a menudo no solo biológicamente difícil sino lleno de escollos legales, al menos en el pasado, y a veces familiares y sociales, episodios compartidos de sus vidas a partir de los cuales crean un discurso de unidad, de biografía común.

"Fue muy difícil, probamos no sé cuántas veces... entramos en una crisis terrible incluso como pareja, me acuerdo una noche que llegamos a preguntarnos qué hacíamos juntas [...] entonces vimos que se nos iba de las manos y cambiamos el plan, no sé cómo le dimos la vuelta" (María, 2017).

"yo lo hice porque la veía tan mal, de verdad, para ella era muy importante" (Ana, 2020).

Isa, que comparte cuidados y crianza con su mujer, de dos niños que ésta traía consigo de una relación anterior, afirma que esos niños son sus hijos y no lo sería más otro que gestara ella:

"Hubo un momento en que mi mujer me dijo si quería hacerlo yo; tenía miedo de que me quedara con las ganas de tener esa experiencia y eso luego fuera peor, pero yo le dije que yo ya tengo dos hijos" [...] "cuando empezamos yo no tenía trabajo, no sabes la de pañales, canciones, paseos por el pasillo [...] cuando la peque empezó a ir al cole aún se hacía pipí y yo venga al colegio a cambiarla [...] como estaba en casa [...] allí era mami para todos" (Isa, 2017).

"Son niños deseados dentro del matrimonio, no es que una venga con su idea y la otra no" [...] "Son hijos de las dos igual" [...] (María, 2017).

"si te dejas la vida ahí, cómo no lo vas a considerar tuyo [...] es que la propia cría se considera tuya... si es que no hago otra cosa, me voy al trabajo y se viene media hora conmigo y luego la bajo al colegio [...] me subo a trabajar y estoy yendo y viniendo... mi vida es Silvia [...] bueno, los dos, pero Óscar funciona ya solo" (María, 2020).

Se percibe, en las afirmaciones de María, como en las de Cecilia, una resonancia que evoca la idea de maternidad intensiva (Hays 1998, citada en Medina, Figueras-Maz, Gómez-Puertas 2013, Gimeno 2018). Se encuentran similares respuestas en otras informantes, lo que hace pensar si se 
sienten presionadas para ser madres más perfectas que las demás, o si son madres como todas, sometidas al esquema invasivo del neoliberalismo materno.

"yo organizo todo mi tiempo libre para conseguir hacer cosas con él. De todas las actividades que salen en la fundación social de mi trabajo, yo me apunto a las que se puede ir con niños y me lo llevo" (Rosa, 2020).

"Aquí somos una unidad y hacemos todo lo que es posible juntas" (Esther, 2020).

"A Carmen le ha molestado alguna vez porque yo cuando llego de trabajar quiero niños y a veces ella echa de menos que hagamos algo solas, creo que es porque los ve más que yo" (Isa, 2020).

Ante estas perspectivas, parece obligada la pregunta por sus vidas de pareja:

"Sí, bueno, es cansado, es difícil [...] no hacemos muchas cosas sin ellos [...] es que son pequeños aún, deberíamos ir pensando" (Esther, 2020).

En todo caso las respuestas refieren una vez más que son madres "como las demás" (Cadoret 2002):

"No sé si sigo algún esquema en su educación, creo que me dejo llevar por el sentido común" (Rosa, 2020).

Ante la consabida pregunta a María sobre si es la madre no biológica afirma:

"yo soy la "no biológica" sí (se ríe), [...] pero como si lo fuera" [...] "Cuando Silvia nació yo estaba en paro y mi mujer trabajaba y me costó encontrar trabajo así que son cuatro años que [...] van los dos pegados a mí, pero vamos la pequeña [...] como un piojillo mío" (María, 2017).

Trasladar la risa, algo sarcástica, de María aquí tiene sentido: El lenguaje no verbal es altamente connotativo. De algún modo manifiesta cierto hartazgo en la clasificación, que en todo caso parece que pretende designarla como por defecto, como a una madre a la que "le falta algo".

La firme defensa de la madre no-biológica supone un neto rechazo a la retórica de la sangre por eso en su "re-naturalización" podrían verse matices de simbolización y casi como ha planteado Butler con respecto al género (1990), una parodia desnaturalizadora.

"Yo creo que eso de la genética está sobrevalorado. No significa nada concreto. Con la genética igual te pones racista que curas enfermedades" (Carmen, 2018).

"Yo creo que eso de "ser de mi sangre" y esas cosas [...] son cosas de abuelas ¿no?" (Esther, 2020).

"¿Tú crees que si hubiéramos adoptado lo íbamos a querer menos o de otra manera?" (Ana, 2020).
De hecho, la deriva que toman las afirmaciones de María, del todo holista y por ende antiindividualista, recuerda a la crítica al mito de la creación de la naturaleza como artefacto moderno (Latour, 1991).

“Es que al final, en una pareja, las dos somos madres biológicas, porque lo sientes igual desde que una de las dos consigue quedarse embarazada, [...] desde antes [...] es una lucha de las dos igual, aparte de que luego tienes que luchar tanto por que se te reconozca, que al final, si cierras los ojos te ves pariéndolo tú [...] la lucha de tanto tiempo [...] además, lo alimentas, lo cuidas" [...] "no sé, nunca pensamos en eso así [...] yo creo que eso de si es mío o es tuyo es cosa más bien de los hombres, de cómo son ellos, entre nosotras eso no es así" (María, 2017).

Hay cierto esencialismo además en las narrativas de María que recuerdan a las tesis del feminismo de la diferencia según el cual habría una ética y un orden simbólico materno frente al masculino (Muraro, 1991). Por otro lado, supone en cierto sentido mantener una idea estereotipada de "los hombres" y "los heterosexuales" (Trujillo y Burgaleta, 2014). A propósito de la cuestión esencialista en torno a la naturaleza diferencial entre hombres y mujeres, durante la investigación predoctoral que está en la base de este artículo, durante una entrevista a una madre heterosexual adoptante se obtuvieron similares respuestas referidas a que "preocuparse por el parecido o si eran suyos o no" eran "cosas de hombres" (Santi, madre adoptiva 2017).

De igual modo, el proceso, como en las parejas adoptantes, homosexuales o no, une por extenuante. En el caso de las madres lesbianas devenir una unidad se cifra en el deseo y en la lucha compartida en un doble nivel: por un lado deben lograr la concepción a través de las técnicas reproducción asistida disponibles con esfuerzo físico, económico y moral, y por otro, encontrar el espacio de reconocimiento legal y social de su familia íntegramente entendida. En algunas narrativas del sufrimiento compartido se evoca el origen del sentimiento de pertenencia (Sahlins 2013).

"a menudo tenemos la impresión de ser una, o de ser una extensión la una de la otra y por cómo nos tratan algunos, creo que hay más gente que lo piensa" (Isa, 2017, en referencia a la batalla legal por su reconocimiento como madre y al hecho de que les intercambian los nombres).

Erica y Vittoria atribuyen al sufrimiento compartido, así como al proyecto vivido intensamente juntas, aun habiendo fracasado su intento de maternidad biológica, la razón de sentirse familia hoy:

"Fue un recorrido intenso, extenuante, doloroso, pero a la vez una experiencia muy fuerte como pareja y estoy convencida de que si no hubiéramos hecho aquello hoy a lo mejor no estaríamos juntas" (Vittoria, 2017).

"Creo que sí, esto ha tenido un peso muy importante en nuestra historia de pareja" (Erica, 2017).

"Es como renacer a partir de lo que no consigues" (Vittoria, 2017). 
“Llegamos a tener que ir a terapia de pareja en aquel tiempo" (Erica, 2017).

Esta unión que describen con esa firmeza se vislumbra en el modo en que hablan del proceso médico o de los embarazos. Utilizan un lenguaje plural que convierte en difícilmente discernible a primera vista quién es la madre biológica. Esta lábil identidad difusa y compartida esconde a la madre biológica o gestante hasta que no se pregunta explícitamente detrás de un uso del lenguaje en plural que invita a interpretarlo precisamente en términos de un fuerte sentido del parentesco como dividualidad holística.

Con referencia a ese sentimiento difuso de ser una sola cosa que está más allá de lo biológico pero pasa por una experiencia biológica, Carla, que no había pensado en tener hijos, narra algo que devuelve la idea de la maternidad intensiva, casi mística, con respecto a la llegada de Vania, su hija adoptiva, desde Nueva Zelanda.

"yo de verdad que no tenía ese sentimiento. No lo habría pensado nunca [...] de hecho cuando Sonia me dijo que volvía con la niña yo creí que sería algo así como un padre... entiéndeme [...] alguien un poco menos íntimo, más externo, [...] pero cuando llegó Vania [...] sucedió [...] en cuanto la vi supe que era mi hija, dormía con ella, pasaba el día con ella, de pronto empecé a pensar en no aceptar más trabajos voluntarios [...] antes hacía muchas cosas así, ahora mi tiempo y mi trabajo son para ella [...] todo es por ella [...] figúrate, casi me vino la leche" (Carla, 2017).

Cabe observar que como en otros casos, se repite el cliché sobre los hombres y la paternidad como un fenómeno ajeno al hecho materno. Por otro lado, resulta interesante señalar que en el relato de su primer encuentro con su hija, Carla hace una clara referencia a cierto enamoramiento inmediato y después, al tiempo transcurrido con el hijo y al cuidado, como sustancia del emparentamiento. Pero termina haciendo referencia a la leche materna como símbolo, fluido tradicionalmente identificado como "substancia" de parentesco (Bestard, 1998).

Así las cosas, en lo referente a la resignificación de la naturaleza, sentir incluso en el cuerpo la maternidad aún sin haber sido la madre gestante aparece en otras narrativas:

"Cuando vi en ella lo que tanto había deseado en mí fue una sensación extraña. Estaba fuera de mí, pero era mío. Viví el embarazo en primera persona de verdad" [...] "no querría a mi hijo más de lo que lo quiero si lo hubiera tenido yo, estoy convencida de ello" [...] "lo sé porque lo tengo todo puesto aquí, no me he guardado nada" (Rosa, 2017).

Cuando ese proyecto no nace de un deseo compartido, tal unidad es menos estable:

"Yo noto mucho la diferencia entre el padre de los niños e Isa, es que a él tuve casi que arrastrarlo para tenerlos y ella llegó y se enamoró [...] de ellos, ¡los quiere más que a mí me parece!" (Carmen, 2018).
"A ver, Alba nació porque yo quería tener una hija, como te decía, desde cría decía que iba a tener una hija que se llamara Alba [...] pero no quería que fuera sola... así que cuando vi que íbamos ya a vivir juntas se lo dije a Cati y bueno ella no estaba tan convencida [...] ahora cuando veo que se comporta como algunos padres pienso que me equivoqué" (Esther, 2020).

Madres iguales, madres visibles

De hecho como también ha observado Imaz (2016a, 2016b) el vínculo de la madre no biológica es reforzado por la propia madre biológica. De hecho, podría interpretarse que ello constituye un rasgo definitorio, y se podría afirmar que identitario de estas familias, pues precisamente la madre no biológica es de algún modo clave en la definición de la identidad familiar, ya que de no existir ella, o si queda invisibilizada, el grupo "madre biológica-hijo" podría percibirse socialmente de manera errónea, como una familia monoparental, y no es esa la identidad que las madres biológicas promueven.

"para mí ha sido muy importante que Isa sea reconocida como madre en todos sitios y por todos, eso es lo que deja claro que somos una familia de madres lesbianas. Lo he defendido hasta en el juzgado, yo creo que más que ella misma" (Carmen, 2018).

"pero ¿cómo no va a ser la madre si lo hice porque ella lo quería?" (Ana, 2020).

"yo creo que tenemos que ser visibles, no podemos no ser naturales. No somos una madre y sus hijos y la otra no se sabe. Somos una familia homoparental y una unidad familiar" [...] "yo le decía a Laura, ¿pero te vas a esperar a quedarte embarazada para decir en tu casa que eres lesbiana? Y así lo hizo, como nos casamos para proteger al crío, fue todo en un año: salida del armario, boda, embarazo y parto" (Esther, 2020).

"no son mayoría pero hay parejas que no entiendes cómo pueden vivir en el armario teniendo hijos, eso sí que hace daño, [...] eso no es sano, es como criar a un niño haciéndole ya ver que hay algo que no está bien en casa, que los demás no deben saber, lo enseñas a esconderse... es como si enseñas a un crío a avergonzarse de su padre... la gente puede vivir en el armario si quiere pero entonces no tengas hijos... yo estuve años en el armario pero cuando pensamos en tener hijos me armé de valor y fuera.. pero fuera fuera [...] que Sandra dice que he salido como un toro" (Cecilia, 2020).

La llamada "salida del armario" puede hacerse esperar pero la publicidad de la relación lésbica desdibujada bajo el velo de "las amigas", es evidente en el embarazo y en especial cuando nacen los hijos. 
"mi madre, que no lo llevaba muy bien, se tuvo que tragar una tarde a Iris que iba diciéndole a todos por la caIle, tengo dos mamás, tengo dos mamás... a la del kiosko, a una amiga de mi madre con la que se cruzaron... a todos" [...] "en el colegio había un niño en infantil que decía que si Iris tenía dos mamás, que él también quería [...] , en fin que el caso es que era vox populi" [...] "Pablo es más silencioso, pero Iris es explosiva... y una vez con cinco años creo llevó una banderita arcoiris a clase. La tenía en su habitación y se empeñó en llevársela. Su maestro fue muy divertido, le dijo, iqué! ¿te has traído la bandera de la república de tu casa?" (Carmen, 2018).

¿Qué somos? ¡Unidad familiar!

Se observa en las narrativas especialmente de las dos mujeres que presentan configuraciones familiares reconstituidas una clara voluntad de validar las unidades familiares actuales en las que se desarrolla la vida, los cuidados y las responsabilidades. En este sentido el uso del lenguaje de parentesco es muy interesante pues si el parentesco en realidad es una forma de relacionalidad (Carsten, 2000) y es por tanto performativo, la pragmática del lenguaje es el nombre de esas realidades resultantes (Moncó y Rivas, 2007).

"No es que Alba le diga "mamá" a Laura pero a veces se le ha escapado" [...] "No sé cómo le llama a Cati cuando está con ella, sé que a mí para hablarme de ella me dice "Cati" y luego a Laura, unas veces le dice de un modo y otras de otro... he notado que desde que ha nacido Dani la ha llamado "mamá" a menudo, es como si quisiera decirnos que ella es nuestra como Dani" (Esther, 2020).

La niña parece estar optando por una lógica de sustitución (Le Gall, Martin, 1993) a juzgar por su uso del lenguaje apelativo y referencial (Moncó y Rivas, 2007).

En todo caso la retórica de la "unidad familiar" es auspiciada por las madres:

"cantábamos con ellos de pequeños una cancioncilla que decía "somos diferentes, somos divertidos, somos interesantes, y nos queremos mucho... ¡somos la familia Gómez López $z^{8}$ !" [...] siempre hemos sentido ser una unidad muy fuerte con ellos y claro que los hemos educado así" (Carmen, 2018).

"tenemos como un mantra que a veces nos disparamos a ver si estás atenta: ¿qué somos? ¡Unidad familiar!" (Esther, 2020).

\footnotetext{
8 Los apellidos son ficticios, como es obvio, y en todo caso el segundo "López", se correspondería con el de la madre no jurídica, que no es oficial para los niños.
}

La familia no se elige

Se ha hablado de la familia por elección por contraste con la familia biológica tradicional (Weston 1997, citado en Imaz 2014) y dado que las familias de las lesbianas son reconocibles como un "nuevo modelo de familia", cabría preguntarles si las lesbianas consideran a las familias como realidades electivas, permitiendo que decidan qué significa "elegir". Cuando se aborda esta cuestión con algunas informantes responden negativamente a esta sugerencia.

"Bueno si dices que mi familia es quien tiene significado para mí, mi apoyo etc. a veces hay amigos que son más eso que tu hermano digamos de sangre... pero no lo eliges creo. A lo mejor querrías que fuera este amigo el que te respondiera y no lo esperabas de este otro, a veces no te esperas quién va a ser eso en tu vida, eso lo sabes después... es que yo creo que esa palabra (familia) se usa para muchas cosas, para lo que se supone que deberían ser algunos y para lo que otros que a lo mejor no tendrían por qué, luego sí lo son" (Carmen, 2018).

"Depende de lo que entiendas por "familia". Yo a mi padre biológico no lo he conocido así que no es mi familia, pero a mi abuela, que sí que es la madre biológica de mi madre biológica, sí es mi familia y yo no he elegido nada, han estado ahí siempre... y bueno luego están las "hermanas"9 claro... pero como que son dos cosas distintas, esas las eliges y no las eliges... hay gente que pasa y gente que se queda" (Daria, 2019).

"No, la familia te cae, pero no digo la de origen, que esa por descontado, digo incluso cuando eliges a tu pareja, al principio no es tu familia y a tus hijos no los eliges tampoco" (Ana, 2020).

¿Deslesbianización de la identidad?

Parece que la preocupación fundamental de las subjetividades silenciadas y los colectivos invisibilizados es, más que nada lograr un espacio social propio y alcanzar así condiciones de ciudadanía y reconocimiento (Honneth 1997). Sin embargo, otra preocupación puede explicitarse

\footnotetext{
9 Nota: en la jerga lésbica italiana, "hermana" ("sorella") significa "ser lesbiana". "Ser una hemana" lo que tiene profundas resonancias en lo que se refiere al parentesco a través de la experiencia e incluso ontológicamente, que no pasa por "tener hijos" (la "hermana" no es la "madre) resuenan otros ecos de parentesco que no son de ascendencia sino entre iguales, asociados al feminismo (en especial el conocido como feminismo de la diferencia, de gran calado en Italia).
} 
conjuntamente, a saber, la de perder algo de sí, la identidad, en un proceso de asimiliación que conduzca a la homogeneización más que a la igualdad. Así ha sucedido con el feminismo, cuyo enfoque desde la diferencia prefiere pensar lo específico a lo universal manteniendo la idea del eterno femenino en autoras como Irigaray (1993) o Muraro (1991). De igual modo, este enfoque, desde instancias postestructuralistas, se ha defendido en torno a la cuestión del matrimonio, la filiación y a la postre, una posible homogeneización, deslesbianización de la identidad en las también llamadas familias homomarentales. Para finalizar esta etnografía se ha procedido a indagar en los sentimientos y opiniones de las informantes al respecto.

"¿deslesbianizarme? yo es que nunca me he identificado así, yo estoy con Clara... desde los diecisiete y nunca he tenido otra relación, yo si lo dejáramos hoy, no sé si estaría con otra mujer o con un hombre... no he tenido ocasión siquiera de pensarlo... vivo así porque vivo bien, esta es mi familia" (María, 2020).

"yo es que todo eso tan sesudo de qué es ser lesbiana... mira, la gente que tiene hijos está a otras cosas... yo sé que hay que ser visible, que hay que hacer activismo cotidiano, yo estoy en un colectivo... no es que no sepa... pero voy a hacer cosas concretas, útiles para otras chicas que igual no han salido del armario y están aisladas o que no tienen información..." [...] "¿Eso de la cultura lesbiana es decir que nosotras no somos lesbianas porque tenemos hijos? Pues si esa es la cultura lesbiana, me quedo inculta" (Cecilia, 2020).

"Entiendo lo que dices... bueno, es posible que hayamos cambiado claro... pero no sé si hemos cambiado en plan ser menos lesbianas... yo sigo viviendo con una mujer... pero claro si tienes hijos... ya no puedes ir con la moto por ahí" (Esther, 2020).

Al insistir en que quizá la opción de casarse es justamente la que es por así decir "anti-lesbiana", que el matrimonio es una institución patriarcal en sí misma se obtienen respuestas incluso jocosas:

"bueno en mi casa es imposible que sea patriarcal, somos dos mujeres" (Isa, 2020).

Tales respuestas no parecen sensibles a la idea de que la definición de "lesbiana", por ejemplo en Wittig, pasa por no ser una "mujer", es decir un objeto construido patriarcalmente (Wittig 2006) y que la maternidad es un "disciplinamiento" del cuerpo de las mujeres (Trujillo y Burgaleta 2014). De igual modo se desmarcan del viejo debate de los años 60-70 sobre la familia monógama y el poder sobre las mujeres del feminismo lesbiano así como de las voces críticas con el proceso de legalización del matrimonio y la adopción de parejas del mismo sexo en España.

"Yo creo que no había ninguna identidad más que lo que te dejaban ser, y ahora simplemente tenemos una vida normal como todo hijo de vecino, hacemos las mismas cosas, claro, porque tenemos los mismos pro- blemas. Antes el problema era otro y de verdad que no lo echo de menos" (Cecilia, 2020).

"Yo creo que no tenemos vida de heteros, tenemos vidas de gente con hijos. Eso no era vida de lesbianas. Salir de cañas sin horario es vida de soltera" (Isa, 2020).

Conclusiones

En la introducción de este trabajo se proponía la indagación sobre las concepciones de familia entre las madres lesbianas, qué definía para ellas el parentesco, qué modelo de familia propician y si sienten o no perder algo de sí, una suerte de identidad, al lograr la igualdad y la visibilidad.

Desde una perspectiva emic, las numerosas conversaciones con ellas y su generosa aportación indican algunas ideas para una abrir una reflexión, no solo en torno al cambio social, ni a la propia idiosincrasia de sus familias como "modelo emergente" (Del valle et al., 2002, citado en Imaz 2006), sino incluso para una reflexión sobre la naturaleza del parentesco en una línea constructivista.

En lo referente al valor otorgado a las substancias biogenéticas en la construcción del parentesco parece haber coincidencias: no valoran la familia como unidad genética, pues el donante aparece en sus narrativas como un elemento abstracto y externo; no se ha hallado incidencia en los discursos sobre la importancia del parecido entendido como"procedencia" pero sí una utilización de la retórica del parecido para señalar copresencia y participación. Insisten en que el vínculo del parentesco sucede en el tiempo y a partir del deseo de ser familia y del cuidado, así como de experiencias significativas e íntimas compartidas, por lo tanto, se refieren a la relacionalidad vertebradora. En ese sentido la madre no biológica es seña de identidad y una clave de visibilidad por lo que la defensa de su estatus es fundamental. A propósito de los modelos seguidos para la construcción de sus familias, no se consideran especiales ni diferentes a los demás padres, hacen referencia al sentido común en la crianza y la educación y no parecen sensibles a una supuesta pérdida de la identidad en el ejercicio de lo que consideran su libertad. Manifiestan una decidida sensación de libertad reproductiva al "decidir" a través de las TRA cuándo y cómo ser madres, asumiendo el beneficio del avance científico por encima de cualquier consideración misógino-ideológica de las TRA (Stolcke, 2018).

Manifiestan lo que hemos interpretado, desde un punto de vista ético, como una forma de holismo y constructivismo familiar, cierto esencialismo y uso de estereotipos de género y un modelo a veces próximo al de maternidad intensiva que las convierte en "madres como las demás".

Son las lesbianas protagonistas de un modo de sentir y producir la familia y los vínculos, es decir, el parentesco, como relacionalidad fundamental o mutualidad del ser y 
por tanto como relaciones sociales. Cambian así el panorama y sobre todo, como han afirmado, de diversas maneras, A. Cadoret, L. Brunet, J. Butler, S. Donoso o G. Trujillo nos fuerzan a pensarnos. En este sentido son sin duda actoras del cambio social, porque además, y sería este objeto de otros posibles estudios, al ponernos ante nuestros propios límites y categorías, invitan, como ha sugerido L. AssierAndrieu (2019) a pensar nuestras leyes como una cultura que está siendo interpelada.

\section{Bibliografía}

ÁLVAREZ, C., PICHARDO J. I. (2017): "Mercancía o don: Bancos de semen y autonomía reproductiva". AIBR, Revista de Antropología Iberoamericana, 12 (3), pp. $339-363$.

ASSIER-ANDRIEU, L. (2019): “Difficulté et nécessité de l'anthropologie du droit", Clio@Thémis, 15, pp. 1-12. http://www.cliothemis.com/IMG/ pdf/ASSIER_ANDRIEU-2.pdf

BADINTER, E. (1991): ¿Existe el amor maternal? Historia del amor maternal. Siglos XVII al XX. Barcelona, Paidós.

BESTARD, J. (1998): Parentesco y Modernidad, Barcelona. Paidós Básica.

BRUNET, L. (2011): "Des usages protéiformes de la nature. Essai de relecture su droit français de la f iliation", en Bonte, P. Porqueres I Gené, E, y Whilgaux, J. L'argument de la filiation. Aux fondements des societés européennes et mediteranéennes. Paris, Editions de la Maison de l'Homme.

BUTLER, J. (1990): Gender Trouble. New York, Routledge, Chapman and Hall.

BUTLER, J. (2002): "Is Kinship Always Already Heterosexual?", Differences, a Journal of Feminist Critique, 13 (1), pp. 14-44.

CADORET, A. (2012): Genitori come gli altri. Torino, Feltrinelli [2002].

CARSTEN, J. (2000): Cultures of relatedness. New a pproaches to the study of kinship. Cambridge, Cambridge University Press.

COBO, R. (2013): “Democracia y crisis de la legitimación patriarcal”, en C. Díaz y S. Dema (eds.), Sociología y Género, Madrid, Tecnos

CORTINA, C. (2016): "Demografía de las parejas homosexuales en España", Revista Española de Investigaciones Sociológicas, 153, pp. 3-22.

DE BEAUVOIR, S. (1998): El Segundo Sexo. Madrid, Cátedra [1949].

DESCOUTURES, V. (2010): Les mères lesbiennes. París, Presses Universitaires de France. https://doi.org/10.3917/puf.desco.2010.01

DOMÍNGUEZ DE LA ROSA, L. y MONTALBÁN, F. M. (2016): “Construcción empírica de la homoparentalidad: necesidad de una aproximación cualitativa", AIBR Revista de Antropología Iberoamericana, 11 (2), pp. 247-272.

ETTELBRICK, Paula L. (2009[1989]): “¿Desde cuándo el matrimonio es el camino hacia la liberación?" en R. M. Mérida Jiménez (ed.), Manifiestos gays, lesbianos y queers. Testimonios de una lucha (1969-1994). Barcelona, Icaria, pp. 217-224 (original en inglés: "Since When is Marriage a Path to Liberation?", Out/Look, 6 (1989), pp. 14-17).

GIMENO, B. y BARRIENTOS, V. (2009):“La institución matrimonial después del matrimonio homosexual", íCONOS, 35, pp. 19-30.

GIMENO, Beatriz (2018): "La maternidad intensiva: la maternidad neoliberal", La Boletina (AMS, Mujeres para la salud), pp. 8-9 (https:// www.mujeresparalasalud.org/laboletina/numero33.html).

GLENDON, M. A. (1989): The transformation of family law. Chicago, The University of Chicago Press.

GOLOMBOK, S., SPENCER, A. y RUTTER, M. (1983): "Children in lesbian and single parent households: Psychosexual and psychiatric appraisal", Journal of Child Psychology and Psychiatry, 24, pp. 551-572.

GONZÁLEZ, M. M., CHACÓN, F., GÓMEZ, A., SÁNCHEZ, M.A. y MORCILLO, E. (2003): Dinámicas familiares, organización de la vida cotidiana y desarrollo infantil y adolescente en familias homoparentales. Estudios e investigaciones 2002. Madrid, Oficina del Defensor del Menor de la Comunidad de Madrid.

GROSS, M. y BUREAU, M.-F. (2015): "L'homoparentalité et la transparentalité au prisme des sciences sociales: révolution ou pluralisation des formes de parenté?", Enfances, Familles, Générations, 23, pp. I-XXXVII.

HONNETH, A. (1997): La lucha por el reconocimiento: por una gramática moral de los conflictos sociales. Barcelona, Crítica.

HOWELL, S. (2003): "Kinning: The Creation of Life Trajectories in Transnational Adoptive Families", The Journal of the Royal Anthropological Institute, 9 (3), pp. 465-484. 
IMAZ, E. (2006): “La maternidad en el seno de las parejas lesbianas: cambios, continuidades y rupturas respecto a los modelos familiares y maternales», Arxius de sociología, 15, pp. 89-100.

IMAZ, E. (2014): "Maternidades lesbianas, nuevas formas familiares y derecho a elegir", GRAFO, working Papers, 3, pp. 6-17.

IMAZ, E. (2016a): ¿Rebiologización en las familias de elección? Lesbomaternidad y uso de tecnologías reproductivas, AIBR Revista de Antropología Iberoamericana, 11 (3), pp. 405-418.

IMAZ, E. (2016b): "Igualmente madres. Sentidos atribuidos a lo biológico, lo jurídico y lo cotidiano en las maternidades lesbianas", Quaderns-e Institut Català d'Antropología, 21 (2), pp. 76-87.

IRIGARAY, L. (1993): Speculum. L'altra donna. Milano, Universale Economica Feltrinelli. [1974] LATOUR, B. (2007): Nunca fuimos modernos. Madrid, Siglo XXI [1991].

LE GALL, D. y MARTIN, C. (1993): "Transitions familiales, logiques de recompositions et modes de regulation conjugale", en M. MEURDERSKLEIN e I. THÉRY, Les recompositions familiales aujourd'hui. París, Nathan, pp. 137-158.

LEACH, E. R. (2004): Rethinking Antrhopology, Londres, BERG [1961].

MARRE, D. (2010): "Antropología y reproducción: Las prácticas y/(o) la ética", Margarita del Olmo Pintado (ed.), Dilemas éticos en antropología: Las entretelas del trabajo de campo. Madrid, Trotta, pp. 93-123.

MAUSS, M. (2010): Ensayo sobre el don. Madrid, Katz Editores [1923].

MEDINA BRAVO, P., FIGUERAS-MAZ, M. y GÓMEZ-PUERTAS, L. (2014): “EI ideal de madre en el siglo XXI. La representación de la maternidad en las revistas de familia", Estudios sobre el Mensaje Periodístico, 20 (1), pp. 487-504.

MONCÓ, B. RIVAS, A. M. (2007): “La importancia de 'nombrar'. El uso de la terminología de parentesco en las familias reconstituidas", Gaceta de Antropología (revista electrónica) art. n. 23.

MONCÓ REBOLLO, B. (2014): “Madres y madrastras: modelos de género, heterodesignación y familias reconstituidas", Feminismo/s, 23, pp. 113-133.

MURARO, L. (1991): L'ordine simbolico della madre. Roma, Editori Riuniti. NEEDHAM, R. (1977): "Introduction", en Rodney Needham (ed.), La parenté en question. París, Editions du Seuil [1971].

ORTNER, S. (1974): "Is Female to Male as Nature is to Culture?", en MicheIle Zimblist Rosaldo y Louise Lamphere (eds.), Woman, Culture and Society. California, Stanford University Press.

PICHARDO, J. I. (2009): "(Homo)sexualidad y familia: cambios y continuidades al inicio del tercer milenio", Política y Sociedad, 46 (1 y 2), pp. 143-160.

PICHARDO, J. I.; STÉFANO, M. y MARTÍN, M. L. (2015): “(Des)naturalización y elección: emergencias de la parentalidad y el parentesco de lesbianas, gays y transexuales", Revista de Dialectología y Tradiciones Populares, LXX (1), pp. 187-203.

PUIGPELAT MARTÍ, F. (2004): “Feminismo y las técnicas de reproducción asistida", Aldaba. Revista del Centro Asociado de la UNED de Melilla, 32, pp. 63-80,

QUINE, W. V. (1974): La relatividad ontológica y otros ensayos. Madrid, Tecnos [1969].

SAHLINS, M. (1990): Uso y abuso de la biología. Una crítica antropológica de la sociobiología. Madrid, Siglo XXI de España Editores [1976].

SAHLINS, M. (2013): What kinship is and is not. Chicago, University of Chicago Press.

SCHNEIDER, D. M. (1980): American Kinship. A cultural Account. Chicago, The University of Chicago Press [1968].

SCHNEIDER, D. M. (1984): A Critique of the Study of Kinship. Michigan, The University of Michigan Press.

SEGALEN, M. (1992): Antropología histórica de la familia. Madrid, Taurus.

STOLCKE, Verena (2018): “Las nuevas tecnologías reproductivas, la vieja paternidad", Papeles del CEIC. International Journal on Collective Identity Research, 2018/2 [papel 193], pp. 1-41. Doi: http://dx.doi. org/10.1387/pceic.20116.
STRATHERN, M. (1988): The Gender of the Gift: Problems with Women and Problems with Society in Melanesia. California, University of California Press.

TATAFIORE, R. (1991): "Amanti in carriera", en AA.VV., Peccati d'Amicizia. Roma, Manifestolibri, p. 139.

THÉRY, I. (1993): Le démariage. París, Odile Jacob.

TRUJILLO, Gracia y BURGALETA, Elena (2014): “¿Queerizando la institución familiar? Entre los discursos bio-sociales y las múltiples resistencias", Feminismo/s, 23, pp. 159-179. Doi: https://doi.org/10.14198/ fem.2014.23.08.

TRUJILLO, Gracia y FALGUERA, Mercè (2019): “'”Es una maternidad que hay que reinventar": madres lesbianas, técnicas de reproducción asistida y retos a los que se enfrentan", Política y Sociedad, 56 (2), pp. 361-380. Doi: https://doi.org/10.5209/poso.60557.

WITTIG, Monique (2006): El pensamiento heterosexual y otros ensayos. Barcelona, Egales [1980]. 